\title{
Using Metaphors to Aid Student Meta-Learning: When You're Learning at Your Best Your Like What?
}

\author{
Sarah Nixon \\ Centre for Sport, Dance and Outdoor Education, Liverpool John Moores University, Liverpool, UK \\ Email: s.nixon@ljmu.ac.uk
}

Received May 30 $0^{\text {th }}$, 2013; revised June 30 ${ }^{\text {th }}$, 2013; accepted July $7^{\text {th }}, 2013$

\begin{abstract}
Copyright (c) 2013 Sarah Nixon. This is an open access article distributed under the Creative Commons Attribution License, which permits unrestricted use, distribution, and reproduction in any medium, provided the original work is properly cited.
\end{abstract}

\begin{abstract}
Metaphors are widely discussed within educational research and this paper adds to the body of knowledge in relation to students using these as a tool to support meta-learning. Metaphors free up space for creative thinking by moving the mind from one place to another and have been found to be an effective cognitive device for learning. This project focuses on what students are like when they are "learning at their best" and discusses what knowing this information does for both individual self-awareness and working with others. Six final year students spent half a day exploring, developing and pictorially representing their "learning at best" metaphors. All six metaphors were different and showed the internal representations of the individuals when they were learning at their best. However out of the discourse common themes arose from the group in relation to what was needed to support learning these included time of day, mood, pace and environment. All six students were positive that the development of personal learning metaphors was beneficial and thought that it was important that these were developed systematically over time. The benefits were highlighted to be both for the individual working on their own and for understanding others in group work situations.
\end{abstract}

Keywords: Metaphors; Learning; Models; Meta-Learning; Student

\section{Introduction}

Metaphors are not a new concept within educational research however this is largely focused on teachers using metaphors (Alger, 2009; Mahlio, Massengill-Shaw, \& Barry, 2010) rather than in this case students developing and understanding their own and each other's. Lakoff and Johnson (1980: p. 5) key authors in the field believe that metaphors are integral to thought and communicate and are "the understanding and experiencing of one kind of thing in terms of another". This paper is not intended to be a theoretical discourse about the role that metaphoric thinking can play in learning but an exploration of intentionally using metaphors as a tool to discover unconscious modes that govern our learning preferences. Crick and Grushka (2009) believe that using metaphors deliberately can be a strategy to convey meaning and it therefore seems that they should have an integral place in education discourse (Cameron, 2003).

This paper explores students developing metaphors about their own learning preferences and how this can be used to both support themselves and their understanding of others. CookSather (2003) in her work with metaphors in education identifies that they can give us new meaning to our experiences. Metaphors can support meta-learning which Biggs (1985) tells us is the development of an awareness of the person as a learner and the application of this knowledge toward becoming effective. There are many different ways of exploring learning and this paper is offering the metaphor as one way that might have value for students and may give them a different perspective on their meta-learning.
Senge (1990: p. 175) writing about mental models within the business environment suggests that they "determine not only how we make sense of the world but how we take action”, however this is pre-determined by the fact that the individual is aware of their own patterns or models which may not always be the case (ibid). Eliciting metaphors as a way of describing mental models can help create awareness, bringing knowledge to the fore and presenting it in a way that others may be able to more easily relate to. "Metaphors give a form to what it is like to be them" (Lawley \& Tompkins, 2000: p. 23). As learning is not always a solitary activity using metaphors to understand oneself and others may be a way to develop and enhance mental models and therefore build on capacity and performance both individually and in a group.

“The discipline of managing mental models-surfacing, testing and improving our mental models of how the world works - promises to be a major breakthrough for building learning organisations” (Senge, 1990: p. 174).

For the past five years within one undergraduate programme in an English university, metaphors have been used as part of personal development planning (PDP), to help students to explore their own patterns of learning. PDP was introduced into higher education in the UK in 2004/2005 (Clegg \& Bradley, 2006) to support students in their personal planning and development (Quality Assurance Agency, 2009). The idea for this work came out of a PDP project where an expert using metaphors to elicit meaning (www.trainingattention.co.uk) was brought 
in to develop strategies to support students in their development and personal understanding of themselves and each other. Approaches to PDP are varied (Clegg \& Bradley, 2006) across the Higher Education (HE) landscape both in the UK, Europe and across Australasia but there is consensus around its practices in helping students structure; plan and reflect on their learning (Quality Assurance Agency, 2009). To do this in a meaningful way is enhanced if the individual understands their ways of thinking and working and their own unique preferences; abilities and attributes. The metaphor is a vessel which can hold this information in a way that can be developed and changed as the individual grows and builds on their learning and understanding; this is known in the field as "emergent knowledge" (Johnson, 2001).

The metaphors in this process have been developed through a set of exercises looking at time; decision making; what's important and the one that has been most meaningful has been around students exploring what they are like when they are "learning at their best". As metaphors are known for their ability to move the mind from one place of understanding to another (Cook-Sather, 2003), this type of creative thinking can enable students to explore their own mental models. The idea around this concept is that once the student understands what they are like when they are "learning at their best" they can recreate the environment, conditions and attitude whenever they need to be in learning mode and therefore be at their best more of the time. If for example a student, when learning at their best resembles a magpie (which is a bird that has a reputation for taking and stashing shiny objects), liking to gather everything and take it back to their nest, this can inform both the students and tutors how they may go about learning and ways they may need to be supported (Nixon \& Walker, 2009). According to Saban, Nazli Kocbeker \& Saban, (2007) building linkages between two dissimilar ideas, in this example learning at best which is the abstract concept and the magpie the concrete, makes a metaphor an effective cognitive device for learning.

As part of the PDP process in this programme the students start to think about the "learning at best" concept at the beginning of their first year they develop their ideas over the first few weeks and then re-visit it at the beginning of second and final year. Re-visiting and updating the model yearly have been found to be an excellent way for the students to reflect on where they are have come from, where they are now and what they need to move forward thereby supporting their meta-learning. The model that they build up becomes more sophisticated over time and on the whole they become more able to both develop the metaphor and also make sense of it both for themselves and others. It is important to note that the staff team working on this programme have been involved in development activities using metaphors to conceptualise ideas in order to help them support the students. This is not an easy process and takes a certain level of awareness from both the staff and students to be able to help facilitate the ideas; thoughts and reflections.

\section{Exploring the Student Metaphors}

In this paper, six students from one degree programme who were coming to the end of their studies were asked to volunteer to undertake a session where they would explore and develop their "learning at best" metaphors. The sample was chosen for convenience and was purposive (Robson, 2002), selected due to the researcher knowing that this group of students were all fa- miliar with this way of thinking. This decision was taken in order that the resulting metaphors would be more easily obtained and developed and therefore detailed, which was important so the resulting metaphors could be used as a resource for other students. All students signed consent forms in which they agreed to the use of their metaphors being shared with fellow students and staff and also being used for the research. The session was videoed and this was used to help support the analysis to construct the detail behind the metaphor as the use of videotaping helped ensure that participants' narratives were accurately presented (Creswell, 2007).

The six students spent a morning with the expert who developed the original approach for the programme, to develop their own metaphor for "learning at best". The facilitation of the metaphors in this session was detailed and in-depth to make them as true a representation of the students ideas as possible. It is acknowledged that they may not be completely accurate in relation to the learning patterns of those students, however they were what those students were thinking at that particular time.

The group then shared their metaphors and asked each other questions to probe for meaning. When each student had developed their metaphor, they drew the idea onto paper and then talked the rest of the group though the image and what it meant to them. The ideas were drawn as images as Palus and Drath (2001: p. 29) proposed that this can "provide a vehicle for fostering a 'mediated dialogue' by helping bridge the gap between the different meaning perspectives of the speaker and listener”. Each metaphor in this paper is described individually with the key ideas being highlighted in relation to the students perceptions of what they needed to learn at their best and their learning preferences. When all six representations were explored key themes did arise that were discussed by a number of the group and these are highlighted in the discussion as they hold valuable information which could be used to support others thinking about their own preferences.

A limitation to the project was that the students undertook the work at the very end of their studies and therefore it was not possible to go back and check with them that the interpretation was as close to their original idea as possible. As this is to be an on-going resource for the next set of metaphors, time will be built in to review the resulting resources with each student to ensure they are accurate and meaningful. The six student metaphors are now shown with the diagrams that they produced and the analysis of the meaning attached.

1) Learning at best is like being a marathon runner. Male student who graduated with a top class degree.

"like a marathon runner, once I get started I keep going and going and then at the end its almost like just forcing myself to go, pushing myself to keep doing it. I like running metaphorical marathons, I enjoy it. The longer the race the better."

The key ideas for this individual, whose metaphor is shown in Figure 1, were about starting on something and keeping going until it was finished, hurdles appear and you have to look beyond them in order to carry on. Hurdles are overcome by asking others, getting help or sometimes just slogging through until you are over it and in this case normally that is about reaching a level of understanding. In the metaphor the sky was grey, "because I am focused, it's not all sunny and blue. I am running under grey skies, it's not miserable it's just focused". You start work "first thing in the morning and stop when it is done".

2) Learning at best is like being a cat. Female student who 


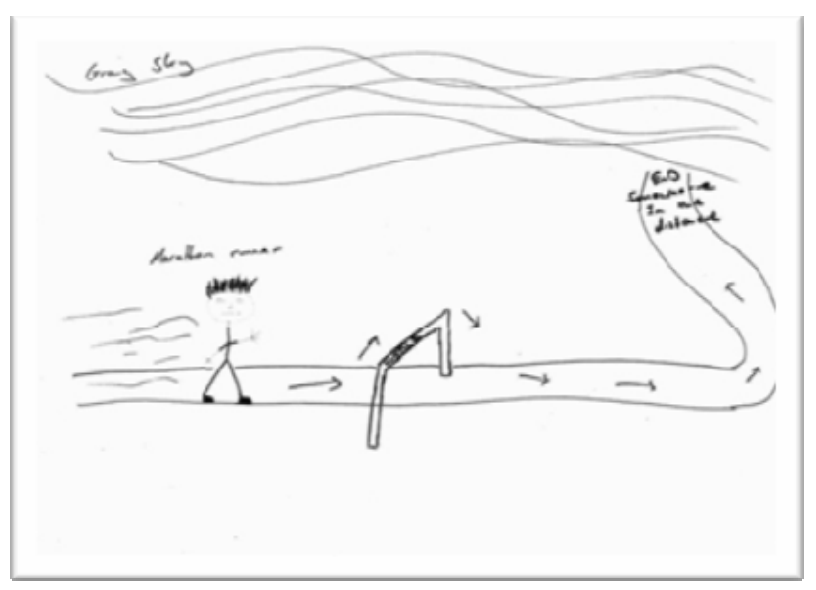

Figure 1.

Marathon man.

graduated with a top class degree.

"I am like a cat that lazes about in the day and doesn't do anything but then at night I wake up and pounce on things. I get great ideas and I use them then whereas in the day I don't know where to get started and I am a bit lazy."

The learning model shown in Figure 2, like marathon man was time affected, this individual came alive at night and during the day was more likely to be resting "when it's sunny I feel like I am on holiday that's when I am most chilled out". This has difficulties when learning in a University system that is based around $9 \mathrm{am}-5 \mathrm{pm}$ and this individual recognised that she had to adapt sometimes when she needed help or had to come into university. However she knew that when she needed to get down to working that it would be in the evening, "I come alive at night" and she needed all her information around her and to hand. If the best work was done at this time then checking and asking questions could be done more in the rest period of the day. To her, mood was crucial "good mood, good marks (marks the biggest thing) then motivation to work".

3) Learning at best is like being a canal barge. These were key forms of industrial transport in the 18th century and now are used for leisure pursuits and holidays. Female student who graduated with a reasonable degree.

"Canal barge, bright, quite loud, going through the country, chilled out, don't get stressed, keep going and then I stop whenever I want. I want to feel relaxed, stop when I want and then start again.”

In the metaphor shown in Figure 3, the time of day did not matter but what was crucial was that the speed was slow and even paced to maximise what needed to happen. When this student understood this about herself she was more able to work towards deadlines and plan her learning more effectively. "I need to listen to music. Music means I am not by myself. Each paragraph needs to be in a different colour to keep attention."

4) Learning at best is like being a chameleon. Male student who graduated with a good degree.

"Chameleon. I can adapt to the environment when I have to. I need to keep changing to satisfy myself and survive. Keeps the learning fresh. If I keep to the same routine it will go down if I change it goes up again.”

This student, whose metaphor is represented in Figure 4, was aware that repeating the same thing over and over resulted

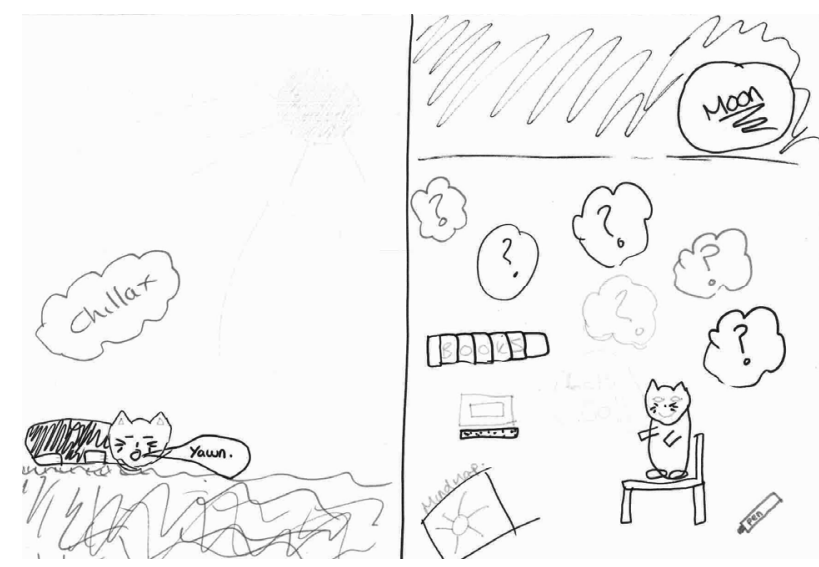

Figure 2.

Cats come out at night.

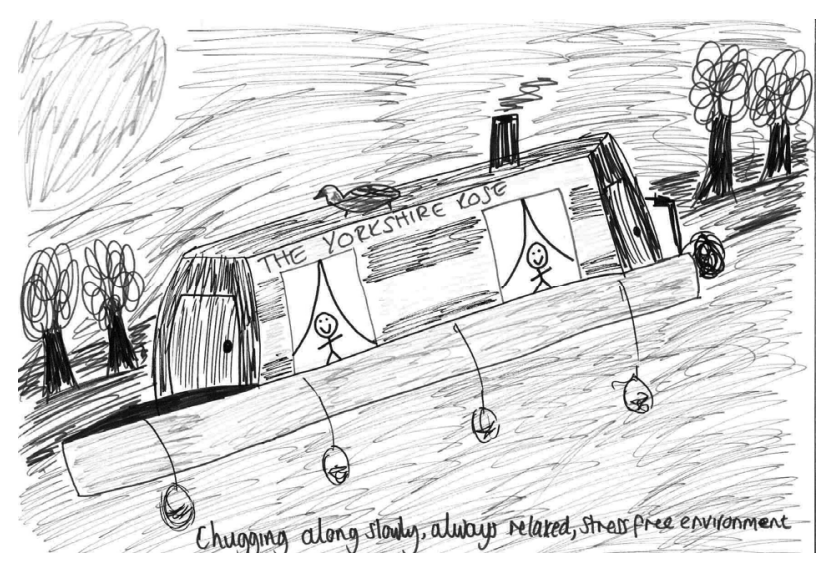

Figure 3.

Canal barge.

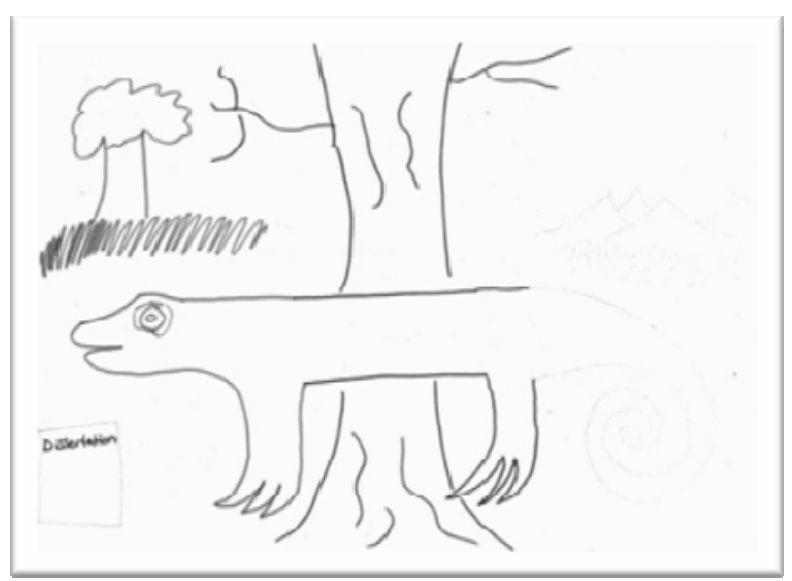

Figure 4.

Chameleon.

in them becoming bored and then less productive "I need to keep changing...just before boredom sets in and I lose motivation I have to change environment or ways of learning. Time period for change varies depends on the mood." The pattern here was for the student to change their environment and patterns every couple of weeks to ensure they could keep motivation levels high. The natural breaks of the academic year worked 
for this student as these gave a natural break.

5) Learning at best is like being a rabbit in the headlights. Male student who graduated with a good degree.

"As soon as the headlights hit me I am engaged. I like to be under pressure. If I don't have the pressure on me I don't do much. The big eyes are shocked eyes, I feel fear and then engage and focus. Without the fear I won't do anything."

This individual was aware that he did not move into action until he really had to, hence describing himself as a rabbit in the headlights as shown in Figure 5. This however upon further exploration was not supporting him as a learner in many ways. "To learn I need something to get my attention." One of the strategies he had adopted was to change the deadlines and make himself accountable to somebody else therefore forcing the headlights to arrive sooner than they might otherwise.

6) Learning at best is like being in a train heading for a wall. Male student who graduated with a good degree.

"On top of the world. I feel confident and I don't feel like I can be beaten. But when I am down I am almost like very insecure and I don't know my direction. I go from one extreme to the other which is the fire and the water. When it clicks into place it continues and continues and then it crashes into a brick wall-almost like a train it's going and stopping and going again. It's a steam train, loud and messy."

This student understood what didn't work so well for him when it came to supporting his learning. "I need to sleep so I am ready and willing to learn. If I work at night it means I cannot sleep as ideas run around in my head and this affects the next day. I have to have silence, noise frustrates me and I get agitated and have to leave, this is when the train will crash.” The student was not completely clear on what needed to happen to move himself from one extreme to the other but stated, "I need pressure to get the train going and I need to know what the end point is and what I am working towards". This is represented in Figure 6 by the train and the wall.
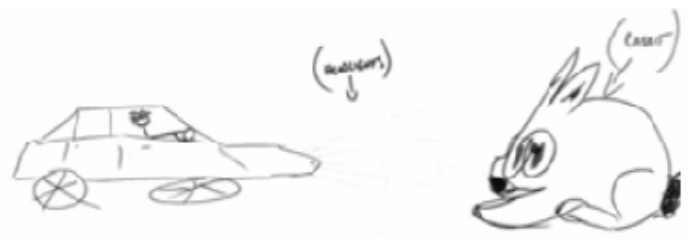

Figure 5.

Rabbit in the headlights.

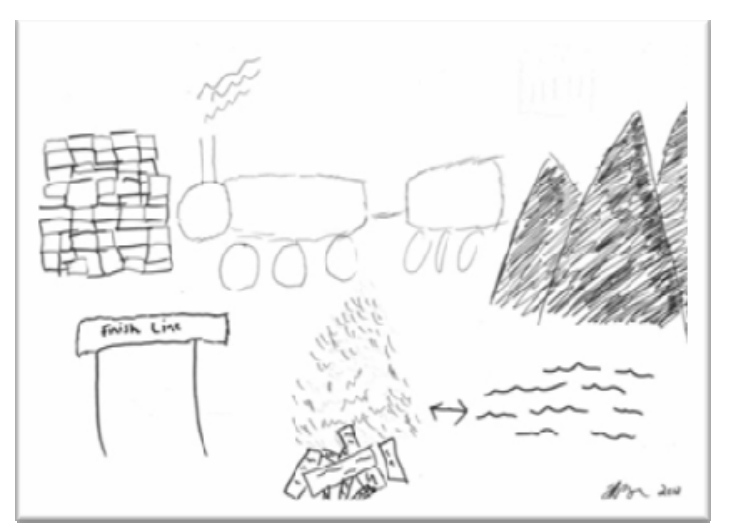

Figure 6.

Train crash.

\section{Discussion}

For each student in this project their "learning at best" model was different although there are some factors that were highlighted across the group that could be drawn upon to help others in developing their metaphors. These included time of day; mood; pace and environment.

The patterns and models we work with are not always helpful, the student who described himself as a chameleon (Figure 4) recalls “It wasn't until I realised that I needed to change my environment and the ways I was working that I was able to sustain learning at my best more of the time". This type of work has implications and can be beneficial for the student themselves for fellow students and developing peer learning groups across a range of disciplines. The idea can also be extended to exploring other avenues e.g. when you're presenting at you best, when your interviewing at your best. Even just knowing what works best can help raise awareness and support meta-learning. The student that used the marathon metaphor in Figure 1 said "using the metaphor does two things, I can ensure I am ready to start running and put myself in that place and I can also use it to tell others where I am up to and if they know my metaphor they will then be able to understand what I need and be able to support me". Metaphors as a learning tool have much strength but also take time to develop for the students as although metaphors are used throughout everyday language (Lakoff \& Johnson, 1980) moving to think about specific things like learning at best and matching a metaphoric concept to this does not always come naturally. There needs to be a developmental process put onto this where it starts with a light touch, so students may talk about needing to be organised, to have all the information with them and to be in a quite space and it may take time for this to develop into a metaphor such as the magpie. The student who compared themselves to the cat, as shown in Figure 2, remembers "I didn't get it at first; I thought it was a bit weird comparing yourself to something else, but when I used the words to explain what I needed to learn at my best the idea for the cat just came and it fits so well with my ways of working". The drawing seems for some students to be a crucial part of the process, "It wasn't until I had drawn the rabbit on paper that it hit home how I was working and what I needed to do to help me" (Figure 5).

\section{Implications}

To support individual students, tutors can explore different elements of the whole metaphor to gain more in-sight and help the individual come up with strategies to support them as learners. For example, with the student who had the train metaphor, the wall can be explored to see what needs to happen so the train does not hit the wall and that they can be "on top of the world" more of the time. In groups the same approach works well as the students can start to ask each other questions and explore how they might go about working together. To make this happen each student needs to spend a little time developing their ideas, prompts from a tutor can help here and then they share their ideas and ask each other questions. A good question to ask to highlight differences is "who's not like that". The students who compared themselves to a cat (Figure 2) and the marathon man (Figure 1), both talked about how they would have to adapt if they were to work together. Suggestions included splitting up the jobs and working on these individually at the best 
time for them and then coming together at a time they both could work with. Just knowing this information can save a lot of unnecessary tension that might just be caused by a lack of awareness. The student that was cat (Figure 2), said "I know that I have to shift my working patterns to fit in with others and knowing what they need makes working in groups so much easier".

The images developed through this project and future metaphors collected can provide the basis for others to start this work with their students. The first point might be to look at the images and discuss what the key features of each metaphor are and what they think these students might have been like. Over the induction period the students could then start to build up their metaphor model and this will need to be re-visited and re-fined over the period of study. Towards the end of the programme and with the students permission these could be then be collected by tutors and made into a resource that was built from within the programme and as the staff would know these students more of the story could be used the following year.

\section{Conclusion}

Metaphors have been widely used and written about in education and this project adds to the body of knowledge as it develops the idea of using them as a systematic tool to enhance student's ability as meta-learners. Using metaphors as a tool for developing meta-learning has been shown to be a positive addition to the PDP experience for the students on this programme. All six students felt that knowing their own model for "learning at best” was of benefit and they all agreed it was a useful way of learning how to work with each other. There is no one answer to the question when I am learning at my best I am like what and the beauty of this is the individual nature of the ideas and their meaning. However there did appear to be some key elements including time of day; mood; pace and environment which will be explored further as this research continues. Alongside this, future research will be undertaken to gather more qualitative data about the student's views on the approach and its impact on their learning.

In relation to this project each picture has been re-drawn by a student on the same programme who is interested in art and each has been annotated with text from the students words to explore some of the meanings that may not be visible diagrammatically. The work has been enlarged and made into a mural on one of the corridors next to teaching rooms with the hope that they will be the start of conversations about learning whilst students waiting to go into sessions. The ideas have been presented at an in-house teaching and learning conference and others were interested in using this idea with their students. The exercises; drawings and student stories are being made into a teaching resource which will be available for other staff who want to integrate this type of thinking into their teaching. It is hoped that the metaphors and pictures may provide for other students the start of a conversation, a light bulb moment, or a chance to explore similarities and differences and in the midst of this to gain just a little more understanding of themselves and how they can learn at their best.

\section{Acknowledgements}

Thanks go to Caitlin Walker (www.trainingattention.co.uk) for her ideas and ability to systemically change thinking. Thanks also to the students who gave up their time and enthusiasm to share their ideas to help others learn.

\section{REFERENCES}

Alger, C. L. (2009). Secondary teachers' conceptual metaphors of teaching and learning: Changes over the career span. Teaching and Teacher Education, 25, 743-751. doi:10.1016/j.tate.2008.10.004

Biggs, J. B. (1985). The role of meta-learning in study process. British Journal of Educational Psychology, 55, 185-212. doi:10.1111/j.2044-8279.1985.tb02625.x

Cameron, L. (2003). Metaphor in educational discourse. London: Continuum.

Clegg, S., \& Bradley, S. (2006). Models of Personal Development Planning: Practice and processes. British Educational Research Journal, 32, 57-76. doi:10.1080/01411920500402003

Cook-Sather, A. (2003). Movements of mind: The matrix, metaphors, and re-imagining education. Teachers College Record, 105, 946-977. doi:10.1111/1467-9620.00274

Creswell, J. W. (2007). Qualitative inquiry and research design: Choosing among five approaches (2nd ed.). Thousand Oaks, CA: Sage.

Deakin-Crick, R., \& Grushka, K. (2009). Signs, symbols and metaphor: Linking self with text in inquiry-based learning. The Curriculum Journal, 20, 447-464. doi:10.1080/09585170903425069

Johnson, S. (2001). Emergence: The connected lives of ants, brains, cities and software. London: The Penguin Press.

Lakoff, G., \& Johnson, M. (1980). Metaphors we live by. Chicago: The University of Chicago Press.

Lawley, J., \& Tomkins, P. (2000) Metaphors in mind: Transformation through symbolic modelling. London: The Developing Company Press.

Mahlios, M., Massengill-Shaw, D., \& Barry, A. (2010). Making sense of teaching through metaphors: A review across three studies. Teachers and Teaching: Theory and Practice, 16, 49-71. doi:10.1080/13540600903475645

Nixon, S., \& Walker, C. (2009). PDP-inspiring capability. In J. Buswell, \& N. Beckett (Eds.), Enhancing student centred learning in business and management, hospitality, leisure, sport and tourism. Newbury: Threshold -Press Ltd.

Palus, C. J., \& Drath, W. H. (2001). Putting something in the middle: An approach to dialogue. Reflections, 3, 28-39. doi:10.1162/15241730152695216

Robson, C. (2002). Real world research (2nd ed.). Oxford: Blackwell Publishing.

Saban, A., Nazli Kocbeker, B., \& Saban, A. (2007). Prospective teachers' conceptions of teaching and learning revealed through metaphor analysis. Learning and Instruction, 17, 123-139. doi:10.1016/j.learninstruc.2007.01.003

Senge, P. M. (1990). The fifth discipline. The art \& practice of the learning organisation. London: Random House.

The Quality Assurance Agency for Higher Education (2009). Personal development planning: Guidance for institutional policy and practice in higher education.

http://www.qaa.ac.uk/Publications/InformationAndGuidance/Pages/Per sonal-development-planning-guidance-for-institutional-policy-and-prac tice-in-higher-education.aspx 